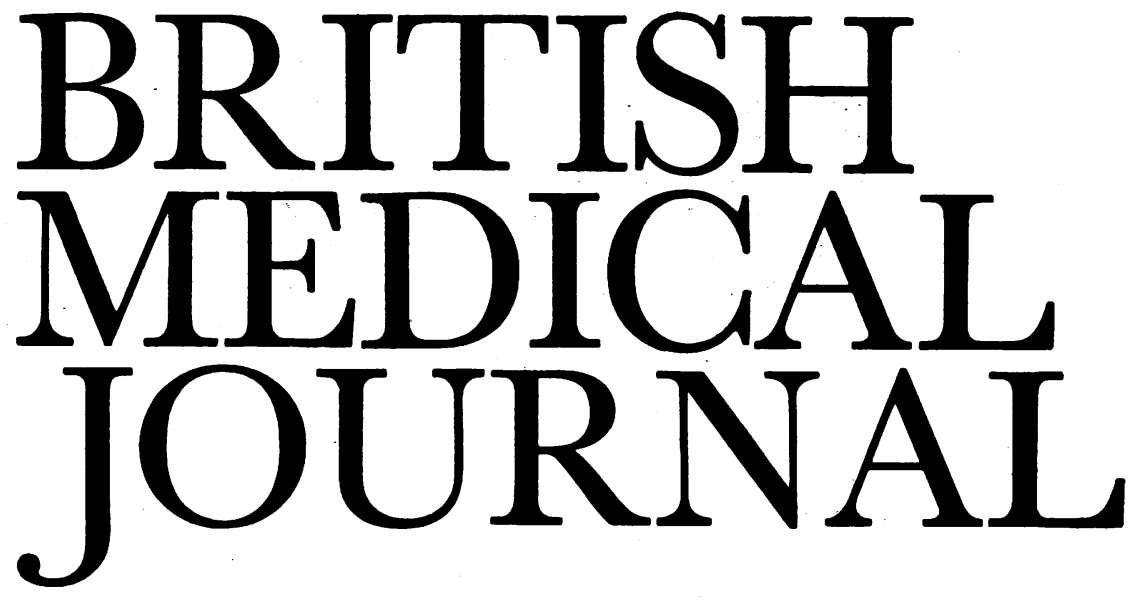

LONDON, SATURDAY 17 JANUARY 1987

\title{
The need for autologous blood transfusion
}

Last week's suggestion that people who have had casual sex in the past four years should not donate blood will have further imperilled Britain's supply of blood for transfusion. It will also encourage further consideration of collecting the patient's own blood before an elective operation and then transfusing it into him during the operation if necessary. The Americans and Australians are already using autologous blood transfusion, and it will surely have to come soon in Britain and other countries. Anxiety about transmitting the human immunodeficiency virus (HIV) is not the only stimulus to autologous blood transfusion. There are also worries about transmitting non- $\mathrm{A}$ non-B hepatitis and an increasing need to use donated blood for purposes other than transfusion as whole blood.

Although all blood donations in developed countries are now tested for antibodies to HIV, concern remains that some donations may transmit the virus. Having acquired the virus a person may take three to six months to develop the marker antibody, and the virus's remarkable capacity for antigenic change may make the antibodies evoked undetectable by conventional testing. ${ }^{1}$ As the virus spreads into the general heterosexual community asking male homosexuals, drug addicts, prostitutes, and their partners to refrain from donation becomes less helpful as èven the traditionally safe volunteer donor may be affected. So far 65 positive donations have been detected in Britain ( $p$ 176).

By 1984 in the United States about $1 \%$ of all cases of the acquired immune deficiency syndrome (AIDS) had been related to blood transfusion, ${ }^{2}$ but by 1986 the figure had risen to $2 \%$ of adult and $13 \%$ of childhood cases. ${ }^{3}$ About $90 \%$ of cases of hepatitis after transfusion are caused by non-A non-B viruses. Non-A non-B hepatitis often causes chronic active hepatitis or cirrhosis and develops in up to $10 \%$ of blood recipients in the United States. ${ }^{45}$ Other infections transmissible by transfusion are cytomegalovirus infection, malaria, and syphilis.

Autologous transfusion eliminates these risks of serious infection and also avoids sensitisation to red cell, white cell, and platelet antigens in donor blood. Febrile reactions occur in at least $2 \%$ of all transfusions, ${ }^{6}$ and an increasing proportion of cases of haemolytic disease of the newborn are caused by sensitisation of mothers to non-self antigens during previous blood transfusion. ${ }^{7}$ If autologous blood transfusion were used for girls and women up to the menopause such cases of haemolytic disease of the newborn could be eliminated. In addition, $7 \%$ of the general population lacks IgA, and for them transfusion often results in allergic reactions and even anaphylaxis.

Autologous blood transfusion was first undertaken on a large scale in 1962 for operations including pulmonary lobectomy and cholecystectomy.$^{8}$ Other groups then began to provide autologous blood for many elective operations," and by 1974 a third of American blood banks offered autologous transfusion, although it was underused because of apathy by patients and doctors and the administrative problems of starting a new system alongside an already functioning one. ${ }^{10} \mathrm{~A}$ similar sporadic and underused system developed in Australia, but in both countries since 1980 the fear of AIDS among the general public has created a new demand for autologous transfusion and a resurgence of interest among doctors. ${ }^{11-15}$ In November 1986 the council on scientific affairs of the American Medical Association called for education of doctors on the benefits and availability of autologous transfusion. As yet few laboratories in Britain provide the service, although it has been advocated. ${ }^{16}$

Blood is best stored in the liquid form with citrate phosphate dextrose with adenine, which gives a shelf life of 35 days. The patients can be aged between 16 and $70,{ }^{17}$ although many programmes take fit patients up to 75 . Autologous transfusion has also been used in young children. ${ }^{18}$ Those with most experience argue that anyone who has normal marrow function and who is fit for general anaesthesia and surgery is fit to donate blood in an autologous transfusion programme. ${ }^{19}$ Patients with cardiovascular disease, severe respiratory distress, or epilepsy are excluded, but autologous transfusion has been used successfully on patients requiring major cardiothoracic surgery. ${ }^{20}$ The haemoglobin concentration must be $110 \mathrm{~g} / \mathrm{l}$ or greater or the packed cell volume $34 \%$ or more. ${ }^{21}$ For women in the last trimester of pregnancy physiological haemodilution means that a lower limit of $105 \mathrm{~g} / \mathrm{l}$ for haemoglobin concentration or $32 \%$ for packed cell volume can be accepted.

Up to eight units of blood (405-495 $\mathrm{ml}$ each) can be withdrawn altogether; blood can be withdrawn as often as every fourth day with the last unit taken no less than three days preoperatively, ${ }^{17}$ but most programmes use only two to 
four units. Ferrous sulphate ( $300 \mathrm{mg}$ thrice daily) is prescribed to ensure maximum bone marrow haematopoeisis. Marrow activity increases threefold to fourfold, achieving an increase in haemoglobin concentration of $10 \mathrm{~g} / 1$ (replacing 1 unit) every three to five days. ${ }^{22}$

All patients so managed arrive at operation with a haemoglobin above $100 \mathrm{~g} / \mathrm{l}$, which is considered safe by most anaesthetists. ${ }^{23}$ Most patients experience a drop of about $12-20 \mathrm{~g} / \mathrm{l}$ in haemoglobin concentration and $2 \cdot 5-7 \%$ in packed cell volume. This drop in packed cell volume is potentially beneficial-reducing whole blood viscosity, improving capillary perfusion, and reducing the chance of thrombosis. Also the marrow is maximally active at the time of operation and better able to replace any blood loss above that provided by autologous transfusion.

Careful and distinctive labelling of autologous blood and storage separate from traditional donor blood are essential. The hazard of misidentification is as great as with homologous donor blood and can lead to catastrophic haemolytic reactions. The only pretransfusion testing of autologous blood required by the American Association of Blood Banks is ABO grouping, which could lead to an important cost saving. Many practitioners, however, subject autologous blood to exactly the same testing as donor blood-including screening for hepatitis and syphilis and full cross matching against a pretransfusion blood sample.

Autologous transfusion programmes have been used successfully in orthopaedic surgery, ${ }^{24}$ including paediatric cases, ${ }^{18}$ cardiothoracic ${ }^{20}$ and general surgery, ${ }^{25}$ and urological ${ }^{26}$ and head and neck surgery. ${ }^{27}$ It has also been used for women undergoing caesarean section..$^{28}$ As many as $55 \%$ of elective surgical operations could be performed using autologous blood-that is, about a quarter of all surgical operations. ${ }^{15}$ The success of an autologous transfusion programme depends very much, however, on the enthusiasm of the organising staff and the motivation of patients. Milles, in a review of autologous blood transfusion in over 1000 patients, found that this method of blood replacement covered $90 \%$ of current transfusion needs at Chicago State Tuberculosis Sanatorium. ${ }^{19}$

Peters and Hölke reported their experience of autologous transfusion for 271 patients requiring elective orthopaedic surgery: autologous blood alone was enough for $86 \%$ of those who had predonated $1000 \mathrm{ml}$ of blood and for $65 \%$ of those who had predonated only $500 \mathrm{ml}$ of blood. ${ }^{29}$ In a smaller study Blaise and Jackmuth found that $85 \%$ of those requiring total hip replacement could be covered with autologous blood alone. ${ }^{30}$ Davis found that among 137 patients requiring orthopaedic, general, and gynaecological surgery $62 \%$ required only autologous blood, ${ }^{25}$ and $68 \%$ of 155 procedures on children aged 7 to 20 years (average age 14) required only autologous blood. ${ }^{18}$ The experience of Kruskall was less encouraging: over 16 months under $12 \%$ of eligible patients were enrolled into an autologous transfusion programme, and only $37 \%$ of those who did participate were transfused solely with autologous blood. ${ }^{31}$ Fewer than a quarter of all staff surgeons and only half of the cardiologists entered any of their patients into this study. This contrasts sharply with the experience of Milles and shows that success depends on motivation and communication.

A few patients who have unusually severe bleeding will need additional homologous donor blood, but autologous blood that is not needed can be diverted for use by other patients if it has been taken from a patient meeting the standard donation criteria. ${ }^{32}$ If it is out of date and from an acceptable autologous donor the plasma can be used to produce albumin, which is in short supply.

The disadvantages of autologous blood transfusion ar尺 mainly logistical. The setting up of such programmes needs scrupulous attention to detail and cooperation between surgeons, anaesthetists, local blood banks, and central trans fusion services. In the present climate patient compliance is unlikely to be a problem.

There are few comparisons of the cost effectiveness of. autologous and conventional transfusion programmes. The consensus appears to be that there is an initial "start up" cost because autologous transfusion is usually provided in the centres at which the operation is to be done rather than inf centralised regional transfusion laboratories. Once the service is in place and use increases, however, the unit costs fall and are eventually offset by reduced patient morbidity and the diversion of unused blood for use by other patients. ${ }^{17}$ Somè have claimed an overall reduction in costs. ${ }^{1533}$ Anothe $\vec{p}$ benefit is the recruitment of people who might otherwise never have considered it into the population of bloos. donors. ${ }^{25}$

Better tests for detecting HIV may eventually becom available, ${ }^{34}$ but we still have no reliable way of identifying non-A non-B viruses. Furthermore, AIDS is the third? potentially fatal viral disease found to be transmissible by blood - and may not' be the last. Several otherwise healthy people succumbed to hepatitis $B$ and the other viral diseases before these were eliminated from transfused blood. Autoc logous transfusion would have prevented many of thesêّ deaths. To continue to ignore this method of supplying bloog is shortsighted.

L A KA

Consultant Haematologist,

Royal Infirmary,

Sunderland SR2 7JE

1 Public Health Laboratory Service Communicable Disease Surveillance Centre. Report. Br Med 1986;293:326-7.

2 Curran JW, Lawrence DN, Jaffe H, Kaplan J, Zyla LD, Chamberland M. Acquire immunodeficiency syndrome associated with transfusion. N Engl I Med 1984;310:69-75. 3 Council on Scientific Affairs. Autologous blood transfusions. FAMA 1986;256:2378-80.

4 Seeff LB, Wright EC, Zimmerman HJ. Veterans Administration co-0perative study of post. transfusion hepatitis 1969-74. Am J Med Sci 1975;270:355-67.

5 Aach RD, Kahn RA. Post transfusion hepatitis: current perspectives. Ann Intem Mes 1980;92:539-46.

6 Rush B, Lee NLY. Clinical presentation of non haemolytic transfusion reactions. Anaesth Intensive Care 1980;8:125-31.

7 Beal RW. Non-Rhesus (D) blood group isoimmunisation in obstetrics. Clin Obstet Gynaecot. 1979;5:493-503.

8 Milles G, Langston H, Delassandro W. Experience with auto transfusions. Surg Gynecol Obst th

9 Brzica SM, Pineda AA, Taswell HF. Autologous blood transfusion. Mayo Clin Proc 1976;51 723-37.

10 Zuck T. Introduction. In: American Association of Blood Banks, ed. Autologous blood transfusion Washington, DC: American Association of Blood Banks, 1976.

11 Popovshy MA, Devine PA, Taswell HF. Intraoperative autologous transfusion. Mayo Clin Praf 1985;60:125-34.

12 Ibister JP. Strategies for avoiding or minimising homologous blood transfusion. A sequel to the AIDS scare. Med $\mathcal{F}$ Aust 1985;142:596-8.

13 Beal R. Blood banking - public or private, isologous or autologous? Med f Aust 1986;144:393-4N
14 McLaughlin GE. Autologous transfusion endorsed. JAMA 1985;254:507.

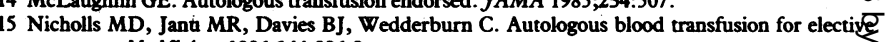
surgery. Med ₹ Aust 1986;144:396-9.

16 James SE, Dodds R, Smith MA. Avoiding AIDS with autologous transfusion. Br Med 1985;290:854.

17 Cable RG. Implementation of a pre-donation system. Int Anesthesiol Clin 1982;20:59-76. 18 Cowell HR, Swickard JW. Autotransfusion in children's orthopaedics. $f$ Bone foint Surg [Am历 1974;56:908-12.
Milles G, Langston HT, Dalessandro W. Autologous transfusions. Springfield, USA: Charles Thomas, 1971.

20 Cuello L, Vazquez E, Rios R, Rafucci FL. Autologous blood transfusion in cardio-vascules surgery. Surgery 1967;62:814-8. 21 American Association of Blood Banks. Standards for blood banks and transfusion servicee
Washington, DC: American Association of Blood Banks, 1981 .

22 Zuck T. Donor response to pre-deposit autologous transfusion phlebotomy. In: Americap of Blood Banks, 1976.

23 Allen JB, Allen FB. The minimum acceptable level of haemoglobin. Int Anesthesiol Che 1982;20:1-22. 
24 Turner RS. Autołogous blood transfusion for surgical auto transfusions. $f$ Bone foint Surg 1968;50A:834.

25 Davis R. Banked autologous blood for elective surgery. Anaesth Intensive Care 1979;7:42-4. 26 Swanson D, Lo RK, Lichtiger B. Pre-deposit autologous blood transfusion in patients undergoing radical cystectomy. F Urol 1983;130:892-4.

27 sands GJ, Wood RP, Van Schoorhoven PV. Autologous blood transfusion in head and neck surgery. Arch Otolarynogol 1968;88:423-5.

28 Milles G, Browne WH, Barrick RG. Autologous transfusion for elective Cesarean section. Am $\mathcal{J}$ Obstet Gynecol 1969;103:1166-7.

29. Peters Von M, Hölke D. Autologe Transfusion an einer orthopädischen Klinik. Anesteziol Reanimatol 1985;10:323-8.

30 Blaise G, Jackmuth R. Pre-operative autotransfusion for total hip prostheses. Acta Anoesthesiol Belg 1979;3:175-82.

31 Kruskall MS, Glazer EE, Leonard SS, et al. Utilisation and effectiveness of a hospital autologous pre-operative blood donor program. Transfusion 1986;26:335-40.

32 Kay LA, Huehns ER. Clinical blood transfusion. London: Pitman Medical, 1985:229-30.

33 Newman MM, Hamstra R, Block M. Use of banked autologous blood in elective surgery. JAMA 1971;218:861-3.

34 Allain JP, Laurian Y, Paul DA, Senn D. Serological markers in early stages of human immunodeficiency virus in haemophiliacs. Lancet 1986;i:1233-6.

\section{The flow cytometer}

The flow cytometer is one of the most exciting of recent innovations in pathology. ${ }^{2}$ It produces measurements on thousands of cells that are forced one by one at high speed through a focused light beam (usually produced by a laser). Some of the information that would be available from a microscope can be gathered in this way, but, in addition, the cytometer assigns accurate quantitative values to the information, computes the inter-relationships between the measurements, and may then sort out from the original samples cells with particular characteristics. One possibility is thus that cervical screening might be automated, but the technology is not yet good enough.

The cytometer measures simultaneously the forward and lateral light scatter (proportional to cell size and cytoplasmic optical "texture" respectively) and the intensity of any fluorescence deriving from DNA or protein seeking fluorescent tracers to which the cells have been exposed. Such tracers include DNA binding dyes (for nuclear DNA content) and a potentially limitless range of antibodies to cellular constituents, tagged with fluorochromes. Suitable fluorochromes are fluorescein and phycoerythrin, which emit at different wavelengths and so allow simultaneous double labelling.

Flow cytometers require the cells to be in an evenly dispersed suspension. Blood cells come this way naturally, and cytology specimens and lymphoid tissues can be rendered suitable by gentle physical means. Solid tissues must be digested enzymically. Thus the flow cytometer does not give any of the information on cell to cell orientation which is so important in histopathology.

Early research appliations of flow cytometry were in immunology, and modest instruments can provide good immunophenotypes from peripheral blood leucocytes. In the study of tumours applications include estimating the proportion of cells engaged in DNA synthesis and the proportion sensitive to radiation-both useful indices in monitoring treatment. Most useful, however, is the ability to measure the basal DNA content of tumour cells. The degree of DNA aneuploidy is related to the prognosis of tumours at many sites, including ovary and bladder-where histological examination is sometimes an uncertain guide to the aggressiveness of the tumour. DNA content can be measured in nuclei recovered from thick sections of specimens processed in paraffin, ${ }^{3}$ which means that the power of this new technology can be evaluated using stored blocks of tissues from patients whose ultimate clinical progress is already known. We will soon be reading many reports of studies on archival material.

The flow cytometer cannot be used for cervical screening, partly because of inadequate sensitivity. Whereas a good cytologist will be alerted by two or three abnormal cells in a smear of around 15000 cells, the cytometer would barely detect 10 times that proportion. ${ }^{4}$ Another problem is what to measure: DNA aneuploidy, although correlating with the grade of cervical intraepithelial neoplasia, ${ }^{5}$ is not a satisfactory criterion on its own. Better discrimination may be provided by simultaneous analysis of other values, and there are reasons for optimism as more antibodies to tumour markers become available, including some to oncogene proteins that are presumably close to the origins of the neoplastic process itself. An instrument operable by a skilled technician and able to discriminate between normal and atypical smears without error or fatigue would bring solace today not only to the women waiting for smear results but also to doctors, cytologists, and health board administrators -even if it costs (as good ones do) over $£ 150000$.

ANDREW H WYLLIE

Reader in Pathology,

University of Edinburgh,

Edinburgh EH8 9AG

1 Friedlander ML, Hedley DW, Taylor IW. Clinical and biological significance of aneuploidy in human tumours. $\mathcal{F}$ Clin Path 1984;37:961-74.

2 Quirke P, Dyson JED. Flow cytometry: methodology and applications in pathology. $\mathcal{J}$ Pathol 1986;149:79-87.

3 Hedley DW, Friedlander ML, Taylor IW, Rugg CA, Musgrove EA. Method for analysis of cellular DNA content of paraffin-embedded pathological material using flow cytometry. $\mathcal{F}$ Histochem Cytochem 1983;31:1333-5.

4 Valet G, Ormerod MG, Warnacke HH, Benker G, Ruhenstroth-Bauer G. Sensitive three parameter flow cytometric detection of abnormal cells in human cervical cancers: a pilot study. $\mathcal{f}$ Cancer $R$ es Clin Oncol 1981;102:177-84.

5 Jakobsen A, Back Kristensen P, Krist Poulson H. Flow cytometric classification of biopsy specimens from cervical intra-epithelial neoplasia. Cytometry 1983;4:166-9.

\section{The economics of mental health services}

The most cost effective way to deliver mental health care is not clear. ${ }^{14}$ In the move from hospital to community care the patterns of use and financing of mental health services are changing rapidly - as are the distribution and responsibilities of staff. And developing optimal services is difficult because of the lack of reliable measures of process and outcome and of the costs and benefits of identification and treatment.

In fact, different types of hospital care result in similar clinical and social outcomes. In one study newly admitted patients were randomly assigned to standard inpatient care followed by outpatient care, brief admission followed by discharge to outpatient care, or brief admission followed by day care and then discharge to outpatient care. ${ }^{5}$ Brief admission followed by either day or outpatient care was less expensive after two years than standard admission both in hospital costs and in costs to the patients' families. In a similar study patients admitted as emergencies with neurosis, personality disorder, or adjustment reaction were randomly allocated to day hospital or inpatient care. ${ }^{6}$ After one year the median length of stay for day care was twice as 